\title{
Consideraciones deontológicas del tratamiento de la juventud en los medios de comunicación
}

Recibido: 10 de diciembre de 2010

Aceptado: 17 junio de 2011

Publicado: 31 de octubre de 2011
Juan Carlos Suárez Villegas

jcsuarez@us.es

Universidad de Sevilla (España)

Resumen: En este artículo se reflexiona sobre la juventud como una etapa de transición y cambio en la vida humana que se presta con facilidad a una multitud de interpretaciones simbólicas en los medios de comunicación. Los jóvenes representan con frecuencia un icono de la ruptura del orden social establecido, con lo que se incurre con facilidad a especular sobre autoria en cualquier hecho de carácter delictivo. Por otro lado, se refleja una imagen lúdica desproporcionada con su realidad y sus esfuerzos por formarse e integrarse en el mercado de trabajo. En cambio, son utilizados como símbolos de la promesa de futuro en los mensajes políticos. Esta ambigüedad puede acarrear un estereotipo de los jóvenes que condicionen su percepción por parte de los mayores. En este artículo se proponen medidas para mejorar la imagen de los jóvenes en los medios de comunicación.

Palabras claves: Juventud, medios de comunicación, estereotipos, orden social, deontología.

Abstract: This article reflects on the Youth as a stage of transition and change in human life that has been interpreted, in many ways, by the Media. Young people often represent an icon of the breakdown of social order, which incurred easy to speculate on authorship in any act of criminality. On the other hand, reflects a confused image of proportion to its reality and its efforts to train and integrate into the labor market. Instead, they are used as symbols of the promise of future political messages. This ambiguity can lead to a stereotype of youth condition their perception of the elderly. This article suggests ways to improve the image of young people in the Media.

Key words: Youth, Media, Stereotypes, Social Order, Ethics. 


\section{Introducción: características de la juventud en la sociedad actual}

Reflexionar sobre la juventud y su imagen en los medios de comunicación social, en el inicio del siglo XXI, plantea la necesidad de delimitar y definir los ámbitos del análisis. Posiblemente sean necesarios otros criterios y nuevos marcos de referencias para observar, con ciertas garantías de éxito, a una juventud a comienzos de siglo cuyo universo sociocultural está marcado por las singularidades propias de este momento histórico (económicas, políticas, medio ambientales, demográficas, globalizadoras, entre otras).

Las primeras consideraciones que podemos realizar en torno a la juventud y que definen su perfil como colectivo sociológico son las siguientes:

1.1. El horizonte de madurez de la juventud actual está amenazado por situaciones críticas de enorme trascendencia: falta de empleo, acelerada competitividad en todos los ámbitos de su entorno; dificultades objetivas para la creación de una familia; carestías y dificultades económicas; problemas para enfrentarse con su realidad social. Todo ello provoca incertidumbre, porque siendo como son "los jóvenes del desarrollo económico, democrático y social" cuando les toca el relevo, se encuentran ante una sociedad que les pone dificultades para acceder a los puestos de responsabilidad. Las generaciones anteriores se perpetúan en los órganos de decisión y gestión. Ello provoca en los jóvenes frustración y alejamiento de los centros de interés institucional y falta de incentivos en la participación social $^{2}$.

1.- Hay que empezar indicando que la juventud se caracteriza por la ausencia de uniformidad: cualquier predicado genérico que se formule sobre su situación es, por su propia naturaleza, una verdad parcial. No resulta posible considerar a la juventud como un grupo social monolítico, por la enorme heterogeneidad en la situación y experiencias concretas. La diversidad en las condiciones vitales de los jóvenes es tan acusada que, en muchas ocasiones, no coinciden más que en la edad, pues sus aspiraciones, comportamientos o vida cotidiana no guardan ningún parecido. Así, podríamos referirnos a jóvenes trabajadores, estudiantes o en paro; residentes en pueblos, ciudades o suburbios de un área metropolitana; solteros o casados; con hijos o sin ellos; emigrante o no, etc., configuran experiencias vitales diametralmente plurales, para poder hablar con propiedad de "juventud" en singular. Esta no existe como realidad homogénea.

Solo los medios de comunicación y la publicidad proyectan, seguramente de forma interesada, un modelo bastante homogéneo de juventud urbana, consumista, de clase media-alta, roquera y marchosa ("juerguera"). Bourdieu (1990: 166) ya advirtió del error de tratar a los jóvenes como grupo uniforme y estimaba una manipulación evidente definirlo como grupo constituido dotado de intereses comunes, y relacionar estos intereses a una edad definida biológicamente: "Es necesario analizar las diferencias entre las juventudes o, por lo menos, entre dos juventudes: los jóvenes que están ya integrados en el trabajo, y los adolescentes de la misma edad (biológica) que son estudiantes. En pocas palabras, sólo por un enorme abuso en el lenguaje pueden subsumirse, bajo un mismo concepto, universos sociales que no tienen prácticamente nada en común".

2.- Goodman (1971) en su trabajo Problemas de la juventud en la sociedad organizada, en relación con las posibilidades de integración del joven al mercado de trabajo, comenta: "La mayoría de los jóvenes se enfrentan con la alternativa siguiente: o bien la sociedad es un lugar benevolentemente y frívolo en donde uno puede arreglárselas para llevar una vida trivial, pero con todo menos provechosamente que los más privilegiados, o bien la sociedad es seria (y los jóvenes esperan que lo bastante benévola para aguantarlos), pero en ese caso ellos son inútiles y se hallan irremediablemente excluidos. Tales pensamientos no son muy alentadores para una existencia productiva. Es evidente que la gente joven es mucho más optimista y aspira a un trabajo humano, pero son pocos los que consiguen encontrarlo. Algunos aspiran a un 'buen trabajo'; muchos aspiran a un trabajo trivial, mientras que los demás, cada vez más numerosos, no aspiran a ninguna colocación” (1971: 48). Y como señala más 
1.2. Entre los jóvenes existen dificultades para desarrollar un proyecto de vida personal y estable. Su permanencia excesiva junto a los padres es consecuencia de una precariedad que puede llegar, en algunos casos, a ciertos grados de pobreza. Contrariamente, en aquellos otros que han tenido la oportunidad de conseguir puestos de trabajo con ciertas responsabilidades sociales, políticas y económicas, se observa un incremento de los contravalores de competitividad e insolidaridad.

1.3. Siendo como es la familia, la primera institución social y el lugar donde el joven se adiestra en la participación social, es conveniente hacer algunas reflexiones específicas sobre los actuales comportamientos que se perciben en su seno y las nuevas relaciones entre padres e hijos. Es en la misma familia donde se le indica una ética de comportamiento contradictoria. La experiencia de los padres les describe un modelo social dominado por intereses económicos y políticos. Los hijos captan que el discurso vital de sus padres, a pesar de las enseñanzas que prediquen, pasa por el abandono del hogar a cambio de una dedicación plena a los proyectos profesionales o personales y un modelo de familia "hotelero", donde todos ocupan sus habitaciones durante la noche, sin que exista comunicación efectiva entre sus miembros el resto del tiempo. La ocupación en tareas laborales fuera de casa de ambos progenitores conlleva una desatención de la vida de los hijos y de su educación, en la que se incluyen no sólo conocimientos y actitudes, sino el afecto y comunicación que supone toda relación humana.

1.4. Sus valores están determinados por la necesidad de adaptación al modelo que heredan y su respuesta inmediata se acomoda a las peculiaridades de su generación: están mejor escolarizados, son más realistas, están desencantados, son más racionales, cultos e individualistas; su cosmovisión, determinada por la tecnología audiovisual, les permite ser más cosmopolitas, tolerantes, irónicos y críticos. Pero todo ello provoca perplejidad, nihilismo e inseguridad. Al no encontrar o tener dificultades para conseguir un primer puesto de trabajo, se genera en ellos una gran desconfianza en lo político; no asumen, en su mayoría, las ideologías tradicionales (las defendieron sus padres y tuvieron éxito) e ignoran la moral teocrática de sus abuelos.

1.5. Los procesos de aculturación global del mundo contemporáneo les induce a una homogeneización formal que influye substancialmente a la hora de participar. Adquieren roles de comportamiento a veces muy alejados de su cultura. Este fenómeno genera contradicciones y un cierto caos a la hora de asumir los elementos simbólicos de la realidad cultural presente. Pero los utilizan como argumento contra un modelo que les reporta insatisfacción y frustración.

1.6. La práctica participativa de los jóvenes se caracteriza por el hecho de que estos han ganado en el terreno social, pero no se han visto favorecidos por el desarrollo de algunos derechos (igualdad ante la ley, libertades ideológicas, trabajo, familia, entre otros). Así, poseyendo posibilidades de formación e integración social, no tienen las suficientes responsabilidades comunitarias, políticas, económicas e institucionales; han ganado en el desarrollo de las dimensiones de su personalidad, pero no en presencia público-social. Han

adelante, “cuando uno no hace nada, se ve amenazado por la pregunta; ¿No soy nada?” (1971: 56), situación que expresa en buena medida la crisis de identidad de la juventud. 
sufrido los avatares uniformadores de una sociedad neoliberal (capital, tecnología, medios de comunicación), mientras que la cultura juvenil se va fragmentando ante esta agresión continuada.

1.7. La libertad no ha impregnado totalmente el tejido social. El joven sigue estando presionado o al menos dirigido en sus opiniones por determinados modelos tradicionales, herencia de una forma unilateral de entender la realidad. Cuando se plantean fórmulas de ruptura, el control social penaliza las actitudes de vanguardia, abortando cualquier iniciativa. Esta tendencia se ha incrementado en los últimos años y es opinión de los jóvenes que no puede haber participación sin un grado de libertad para poder opinar sin presiones del entorno.

\section{Síntomas del desencanto}

Esta situación produce en los jóvenes los siguientes síntomas de su actitud ante la vida:

2.1. Se generan búsquedas de refugios físicos y psíquicos a su impotencia y a la falta de perspectivas de todo tipo, con un constante escapismo hacia modos y aptitudes que, en algunos casos, provocan agresividad (contenida o patente) en los sectores juveniles menos integrados socialmente.

2.2. El joven utiliza la institución sin intervenir en su gestión y programación (están diseñadas y realizadas por los adultos). Por ello, solo confían en productos alternativos, cuya administración y desarrollo sí les permite participar y generar cambios (ONG, Movimientos alternativos, ecológicos, okupas [squatting], insumisos [antibélicos, pacifistas], entre otros). Es evidente que las respuestas de las instituciones públicas obedecen más a situaciones coyunturales y/o críticas más preocupadas de la imagen (modelos y estereotipos) que de romper la dinámica de la falta de participación.

2.3. Una situación vital de espera, justamente en la etapa de la vida que se caracteriza principalmente por el dinamismo y las ganas de realizar cualquiera actuación en la que el individuo experimenta sus posibilidades de integración en la sociedad.

En consecuencia, la juventud constituye un período en sí mismo de un desorden reorganizado que se expresa en su condición indómita, que adquiere un cierto carácter metodológico para expresar la reivindicación de independencia frente a sus tutores ${ }^{3}$. Los

3.- Según Iglesia de Ussel (1998: 130-131) el aparente conflicto intergeneracional es más un tópico de la cultura popular (sostenido interesadamente por los medios de comunicación) que contrasta con una experiencia que se muestra más apacible que tensa. En buena medida, esta situación ha sido propiciada por la influencia de los jóvenes sobre sus padres, normalmente eclipsada por la tendencia a contrastar las relaciones entre generaciones más que sus procesos de mutua comprensión. "Las imágenes siempre más populares, de la ruptura generacional, ensombrecen una convivencia más apacible que tensa [...] quizá lo ocurrido deba interpretarse a la luz de las influencias de los hijos en los padres. La cara oculta de las relaciones intergeneracionales, que siempre se contemplan desde los adultos a los jóvenes, y no viceversa. Y, sin embargo, en épocas de intenso cambio social, la armonía familiar tal vez se mantenga o aún se incremente como consecuencia del influjo de los jóvenes en sus padres más que lo contrario". 
comportamientos juveniles que se contemplan hoy en los medios de comunicación como nuevos, tienen en realidad un extraordinario pasado histórico ${ }^{4}$. En anteriores períodos existían comportamientos muy parecidos, que se retoman muchos años después y se mantienen con escasas diferencias sustantivas.

Aranguren (1961), en La juventud europea y otros ensayos, cita la obra de Helmut Scheisky, quien publicó una sociología de la juventud con el título de La generación escéptica. Ya el propio título indica la tesis que sostiene "lo característico de la actual juventud (decía Aranguren en su análisis) es el desplome de los ideales, la desilusión y, consecuentemente, en mayor o menor grado, el escepticismo". Se trataba, sin duda, de una generación escéptica por antonomasia, "tranquila y pacífica, precisamente a causa de su escepticismo, y que cabe caracterizar, asimismo y paradójicamente, como 'juventud adulta'. Son, en efecto, rasgos propios de la vida adulta, y también de la actual juventud, la prudencia y la cautela, la pérdida del gusto por la auténtica aventura, la integración social, al menos en lo exterior, y la búsqueda de un porvenir asegurado".

Esta condición de rebeldía juvenil puede ser valorada de dos modos: como una especie de impedimento para el orden social o como la punta de lanza que preconiza los cambios de tendencias sociales. A este respecto, debería entenderse la juventud como una reserva del ingenio natural de lo humano, acompañada de la fuerza necesaria para hacerla efectiva. Resulta pertinente la observación que al respecto apunta Goodman (1971: 253):

Es absolutamente comprensible y normal que las personas adultas y razonables consideren los desatinos y las absurdidades de la joven generación con una tolerancia matizada de cierta admiración envidiosa, de la misma manera que como unos hechos que nada bueno pueden traer. En los tiempos de Augusto, así como en Inglaterra en el período comprendido entre 1688 y la Revolución Industrial, los excesos de los jóvenes bien educados eran incluso socialmente obligatorios, pues en realidad se trataba de un acto de emancipación. En las épocas agitadas, como por ejemplo en Rusia durante la última mitad del siglo XIX, los jóvenes rebeldes eran considerados como los esperanzadores artífices del cambio social.

\section{La espera como estado vital}

Ya hemos comentado que "el joven" se define sociológicamente por contraste a la supuestamente etapa adulta. La juventud dura hasta el momento de integración al sistema, pues "joven" es quien todavía no reúne condiciones de homologación social: el "no adulto" socioeconómico. A los jóvenes de 15 a 30 años no les queda otra alternativa que dedicarse al estudio y al ocio, mientras aguardan con paciencia la posibilidad de vacantes en el sistema. La falta de expectativas laborales para un alto porcentaje de ellos les obliga a una prórroga forzosa de su juventud, que repercute inevitablemente en la conciencia que tiene de sí mismo (Gil Calvo, 1985: 137):

4.- Por ejemplo, Sócrates afirmaba hace veinticuatro siglos: "Nuestros jóvenes de ahora aman el lujo, tienen pésimos modales y desdeñan la autoridad. No respetan a sus padres ni a sus maestros y son los tiranos y no los siervos de sus hogares. Ya no se levantan cuando alguien entra en sus casas". Con unas u otras palabras, el testimonio recoge apreciaciones muy extendidas sobre el comportamiento de los jóvenes cinco siglos antes del nacimiento de Cristo. 
La juventud es el tiempo que deben esperar los individuos antes de poder ocupar posiciones en la estructura productiva. Los individuos se hacen adultos cuando, al ocupar una posición productiva estable, contraen intereses. Pero, hasta tanto no suceda eso, los individuos siguen siendo jóvenes carentes de intereses que defender: su único interés es el adaptarse al tiempo de espera que les queda.

Esta idea de "la espera" puede ser la que mejor ilustre la situación vital del joven, pues este no puede plantear demasiado pronto sus credenciales para aspirar al sistema. Ante esta situación de perplejidad, "de estar suficientemente preparado, pero ser demasiado joven", no le queda más alternativa que una retórica del ocio. Gil Calvo, ha resaltado (con cierto ingenio) la relación entre el consumo depredador de los medios de comunicación de masas de los jóvenes y las bases fisiológicas de los comportamientos característicos de las ocupaciones ociosas. El consumo audiovisual habría adquirido un valor simbólico de la necesidad de satisfacer la necesidad fisiológica de comer cualquier cosa mientras esperan, sin el efecto pernicioso que el consumo de alimentos tendría sobre su propósito de guardar la línea ${ }^{5}$.

Por otro lado, dicha espera se puede convertir en un vacío vital al no encontrar una correspondencia entre sus esfuerzos y los objetivos en los que desearía que se materializara. Por tanto, el joven advierte una carencia de referentes simbólicos propios con los que identificarse, pues las viejas tradiciones del ciclo de vida de su padre no se corresponden con su realidad. Los jóvenes no pueden soñar tan rápidamente con una independencia efectiva que le permita realizar su propia vida.

El joven ha sido obligado por la sociedad a inventarse un exceso y consumo de ocio. No pueden plantear demasiado pronto sus credenciales para aspirar al sistema. Por eso, ante esta situación de perplejidad, "de estar suficientemente preparado, pero ser demasiado joven", no le queda más alternativa que una retórica del ocio ${ }^{6}$.

5.- A este respecto, comenta Gil Calvo (1985: 109-111): "El tiempo libre puede ser organizado por analogía con las satisfacciones básicas. Embriagarse o drogarse es organizar el tiempo libre por analogía con el sueño; embellecerse (vestido, peinado, calzado, maquillaje, adornos, etc.) es una forma de organizarse el tiempo libre por analogía con el aseo; coquetear es organizar el tiempo por analogía con la genitalidad; los ritos de la oralidad (fumar, beber, picar, chupar, masticar: desde los chicles a los bolígrafos) organizan el tiempo libre por analogía con los ritmos fisiológicos de la alimentación. En efecto, lo que apetece hacer cuando no se tiene nada que hacer es echarse a dormir, rascarse, morderse las uñas, arrancarse piojos o espinillas [...] saquear el frigorífico hincándole los dientes a buen bocadillo hasta desgarrarlo por completo... acciones todas ellas que unos ritmos temporales fisiológicamente específicos, ritmos que pueden ser trasladados a otras actividades de tiempo libre que ya no satisfacen necesidades básicas pero que actúan a modo de sucedáneo [...] Los jóvenes no pueden ponerse a saquear indiscriminadamente la nevera durante su tiempo libre, como querrían, porque engordarían tanto que les sería muy difícil atraer la atención sexual de parejas potenciales. Por ello, sustituyen la depredación de alimentos por la depredación de materiales audiovisuales (moda, imágenes, sonidos) y no porque los materiales audiovisuales satisfacen necesidades básicas, sino porque pueden ser consumidos bajo la misma organización temporal y con los mismos ritmos que la depredación de alimentos, entrándole por los oídos y comiéndose con los ojos: por eso dicen de las chicas a la moda que están para comérselas y de la música bailable que se la siente uno en la barriga".

6.- Erickson (1980: 211) en su conocido trabajo Identidades indica que "la expresión más difundida de la insatisfecha búsqueda de la juventud, así como de su natural exuberancia, es su ansia de locomoción, ya se exprese por un modo enérgico de trabajar, por deportes absorbentes, por bailes muy dinámicos, por vagabundeos y viajes sin rumbo fijo. Además, se expresa mediante la participación en los movimientos actuales (ya se trate de tumultos locales o de desfiles, manifestaciones y campañas de las principales fuerzas ideológicas), si estas apelan a la necesidad de sentirse impulsados y de sentirse esenciales en cuando a impulsar algo hacia un futuro abierto. 
A nuestro juicio, los nuevos símbolos de la juventud están en su forma de divertirse, en los ritos de la fiesta que viene a expresar su propia realidad para el resto de la sociedad: un colectivo gregario que se interroga, afirma o niega en torno a una botella, expresión material del propio signo de perplejidad que caracteriza su tiempo. Diversión y espera unidas en un acto de ruptura de lo cotidiano y cuyas expectativas radican más en la intensidad de lo vivido que en el sentido de una existencia que se extienda en el tiempo.

En este mismo sentido, Bourdieu (1990) ha definido la juventud también como "la tierra del nadie social", en la que se suceden bocetos de identidad que penden sólo de la capacidad de identificación de cada generación. En la juventud, lo simbólico es algo que debe ser reconquistado, pues es propio de ella destruir símbolos heredados. El aparente vacío de los símbolos juveniles expresa un auténtico contenido: el de su condición de nómadas urbanos, buscadores de un destino que deben ir marcando en medio de una nada social.

\section{Simbología de lo lúdico}

Hay un fenómeno de extraordinaria importancia vital: la llamada movida. El éxito de ella reside en el cambio en las condiciones de vida de la juventud durante las últimas décadas. Por primera vez en la historia, una parte muy sustancial de la vida cotidiana de la juventud es prácticamente homogénea. La expansión del sistema educativo (a varones y mujeres, en todas clases sociales y hasta edades más avanzadas) dota de experiencias comunes a sus vidas. La vida escolar constituye un substrato compartido de vivencias, actividad y ritmo cotidiano. Sobre esta plataforma se desarrollan los elementos de una cultura singular de la juventud, propia de las generaciones desarrolladas en la sociedad de la imagen. Una cultura juvenil que, al propio tiempo, la movida manifiesta y expande.

Todos estos elementos dotan de importante contenido colectivo y grupal al fenómeno de la movida, que es mucho más que mero escenario para la diversión individual. Se trata de un instrumento para la preeminencia de lo colectivo sobre el individuo en el tribalismo contemporáneo. El hedonismo de nuestros días, ha destacado Maffesoli, ya no es patrimonio privativo de la aristocracia del siglo XVII y XVIII, ni de la bohemia artística intelectual del XIX y primera mitad del XX: "Actualmente hay una democratización o masificación de este hedonismo que no hace sino traducir la anulación del individuo en un sujeto colectivo".

Al fundirse la experiencia de ocio en el acto grupal de la movida, se perpetúan esa enfermedad del individualismo que es el infantilismo, en el sentido que le dio Pascal Brukner: el "inmaduro perpetuo". La inocencia como parodia de la despreocupación y transferencia a la edad adulta de los atributos y privilegios de los niños. El infantilismo que, con la victimización, permite disfrutar de la independencia y esquivar los deberes del adulto.

\footnotetext{
Es evidente que las sociedades ofrecen multitud de combinaciones rituales de perspectivas ideológicas y de movimientos vigorosos (baile, deportes desfile, manifestaciones, tumultos) a la juventud dispuesta a servir a sus metas históricas y que allí donde las sociedades no lo hacen así, tales pautas buscarán sus propias combinaciones en pequeños grupos que se ocupan de juegos serios, bromas inocentes, o bien crueles y una belicosidad delincuente. Así, pues, en ningún otro estadio de la vida van tan estrechamente unida las promesas de encontrarse a sí mismo y la amenaza de perderse".
} 
La movida opera así como instrumento de consolidación del statu quo al expresar la marginación de la juventud $\mathrm{y}$, al mismo tiempo, perpetuarla creando imágenes de su imaginario privilegio. Por eso, a la movida se le puede aplicar el mismo juicio con que una exitosa escritora catalogaba a los gurús: "Son las antenas de un gran desconcierto social".

Por otro lado, para el joven se han diluido las referencias temporales a largo plazo, que han sido sustituidas por el ciclo de tiempo de la semana, en la que consigue dotar de sentido a sus proyectos vitales. En este horizonte temporal de la conciencia del joven, es normal que el fin de semana tenga cada vez un peso más fuerte. Tanto las botellonas (como cualquier otro tipo de cónclave juvenil) les confiere un cierto sentimiento de continuidad. Lo importante de las botellonas no es beber, sino darle la oportunidad de encontrarse con alguien que le reconozca y otorgue una continuidad a los distintos encuentros semanales. Esta desconexión con el futuro es lo que le permite labrar un horizonte común, aunque sea el simple hecho de encontrarse en el mismo sitio ${ }^{7}$.

Por tanto, el joven encuentra en el tan ansiado "fin de semana" el referente simbólico de la ruptura con el orden semanal y a la vez un referente espacial de su identidad: "un stop ocupado colectivamente", dentro del que se mueven pero sin salirse. En este contexto, la botellona, es parte del símbolo de la espera: un desafío cíclico, renovador, hasta cierto punto.

Cuando no hay símbolos, se los inventan, pues lo simbólico es totalmente necesario para encontrar en la realidad algún aspecto de nuestra identidad. Los nuevos símbolos de la juventud están en su forma de divertirse, en los ritos de la fiesta joven que viene a expresar su propia realidad para el resto de la sociedad: un colectivo gregario que se apacienta en torno a la forma similar al signo de interrogación de una botella de bebida. Diversión y espera unidas en un acto de ruptura de lo cotidiano y cuyas expectativas radican más en la intensidad de lo vivido que en el sentido de una existencia que se extiende en el tiempo.

Entre estos símbolos, destaca el ritual de beber en grupo. La transición entre la infancia y la edad adulta lleva consigo uno de los primeros episodios de la conciencia humana acerca de lo efímero de la vida, incertidumbre sobre el porvenir. Beber y superar la prueba, como casi todas las experiencias de riesgo, es una manera de tener la sensación de retomar la vida después de atrevernos a comprobar hasta dónde podemos llegar. Este sentimiento que subyace en el espíritu de aventura juvenil encuentra un motivo emblemático en el consumo de alcohol que, por su grado de socialización, le permite al joven asumir el reto con la

7.- Esta conciencia de "desconexión” del futuro también se produce con respecto al lugar geográfico: vivimos en una cultura de los "no-lugares", como ha señalado Auge (1992), pues el hombre actual pasa su existencia en sitios que sólo tienen un valor de tránsito para llegar a otro. Se ha perdido el sentido de la identidad con los lugares y su significado antropológico. Sin embargo, esta sensación contrasta con aquella otra que tiene el joven de estar obligado a esperar (“Esperar, ¿dónde?”). En este sentido, Bourdieu (1990) ha definido la juventud también como "la tierra del nadie social", en la que se suceden bocetos de identidad que penden sólo de la capacidad de identificación de cada generación. En la juventud lo simbólico es algo que debe ser reconquistado, pues es propio de ella destruir símbolos heredados. El aparente vacío de los símbolos juveniles expresa un auténtico contenido: el de su condición de nómadas urbanos, buscadores de un destino que deben ir marcando en medio de una nada social. "Que en esta búsqueda sin respuesta opten por dimensiones de la identidad de tipo generacional, y se definan muchas veces por lo que no son quedando el problema de la autoafirmación individual como una cuestión pendiente hasta la adquisición de la llamada 'madurez' o para el resto de la vida" (Maluf, 1999: 55). 
presunta seguridad de que será una prueba fácilmente superada, pues, como dicen ellos: "bebo, pero controlo".

Por otro lado, las bebidas alcohólicas son productos que permiten establecer un rito propio de socialización que no es exclusivo de los jóvenes, como bien sabrá quien haya asistido a cualquier evento festivo. Máximo simbolismo adquiere el alcohol para el joven si tenemos en cuenta las siguientes razones:

- Es un modo de compartir una misma experiencia con alguien mientras habla, dosificando el tiempo en un acto común. Hasta cierto punto, beber es un cronómetro de la relación, un símbolo por el que podemos medir el deseo de estar o no con otras personas.

- La publicidad se encarga de reiterar sus efectos desinhibidores y su facultad para atraer la atención del otro sexo a través de situaciones lúdicas y desenfadas, o bien, por el misterio del romance escondido entre la muchedumbre.

- Es uno de los productos que adquiere una fuerte connotación de status del adulto, pues además de ser identificado como "cosas de hombres", se trata de realizar actividades prohibidas como prueba de autoafirmación que se va buscando de manera paulatina.

- Beber, y hacerlo de un modo excesivo, constituye una de las posibles formas de drogarse para desinhibirse de situaciones personales. Desde esta perspectiva, beber tiene que ver, en cierto sentido, con un cierto castigo que se impone el joven a través de una opción de escapismo aparente por la que se cree protagonista del momento.

- Por último, existen factores puramente coyunturales como el hecho de beber más por una falta de sensación de lo barato que resulta el autoconsumo de alcohol compartido con otros colegas, en contraste con los precios que se pueden encontrar en los establecimientos. Este falso espejismo puede propiciar un consumo excesivo por una actitud de aprovechar el gasto común realizado.

Este proceso, que en sí mismo no tendría por qué tener efectos perniciosos para la juventud, lo adquiere desde el momento que se convierte en un ciclo de consumo. En este punto, hay que evocar no sólo la influencia de la publicidad con su insinuación de los efectos lúdicos y socializadores de la bebida, sino el discurso de los medios de comunicación en su conjunto ${ }^{8}$.

A modo de conclusión de este apartado, creemos que la movida se puede caracterizar por

8.- ¿Qué joven cuando escucha la radio, su compañero de habitación más frecuente, no se encuentra constantemente el mensaje de sobrellevar la semana en espera del "fin de semana" como el espacio de tiempo para el que parecen vivir durante el resto de los días? Cualquier radioyente de las cadenas juveniles advertirá cómo el locutor mantiene una retahíla cansina en la que expresa la visión del tiempo que los jóvenes tienen asumida: el hastío del lunes, porque hay que trabajar; la mejor situación de un martes y del miércoles; el prometedor jueves que nos acerca al fin y "San Viernes", el comienzo del fin de la vida, de la diversión. Este proyecto de organización del tiempo que se le propone a los jóvenes, mientras escuchan música, una de sus actividades favoritas, no es inocente. Responde a la visión que el mercado tiene de los jóvenes. Estos ejercen su condición de consumidores en tanto que tienen tiempo de ocio y esto ocurre en los fines de semana. El fin de semana es un gran negocio del mercado cuyo principal cliente es el joven. 
dos notas particulares en la psicología de los jóvenes:

4.1. La movida ${ }^{9}$ constituye una reunión de negocios para los jóvenes, y de los negocios más genuinos que se producen en la vida, pues son ellos mismos los que se ofertan para encontrar un encaje dentro del grupo, a partir del cual desarrollarán su personalidad social y descubrirán a aquellas personas con las que ensayar sus sentimientos y afectos.

Por supuesto, con esto no queremos decir que no pueda ser de otra manera, pero lo cierto es que en la sociedad actual en la que se ha acentuado el tribalismo de grupo, esta forma se ha convertido en una infraestructura de la sociabilidad del joven. De hecho, los jóvenes pueden experimentar un cierto sentimiento de verse obligados a asistir a dichas reuniones aun cuando no se comparta necesariamente algunos de sus episodios.

4.2. Con la movida, la juventud reclama la autogestión de su espacio lúdico, quizás de los pocos espacios que le quedan al joven. Además, se rebela profundamente contra las alternativas paternalistas que no corresponden a su perspectiva y sólo contribuyen a reforzar su deseo de independencia y de definición.

No se trata de organizarles la actividad lúdica a los jóvenes; precisamente lo que pretenden con las famosas botellonas es huir de esta vida organizada y crear un nuevo espacio de sociabilidad propio. Las alternativas no pueden ser extrapoladas a los distintos contextos porque la propia idea de adaptación va en contra del espíritu de los jóvenes. El joven desea sentirse joven e importante en algo tan efímero como su momento de evasión. El modo de evadirse es lo más personal, lo que permite crear conciencia de identidad, aunque esta sea la decisión de olvidarse de uno. Pero es un abandono que permite el reencuentro y la posibilidad de contarse a sí mismo la experiencia de haber sido de otra manera o, mejor dicho, descubrirse de más formas y sentirse uno mismo.

Por tanto, las administraciones (además de presentar alternativas de ocio) deberían atender a este sentido de independencia de la etapa juvenil y atender a su modo de reivindicar una seña de identidad que es siempre socialmente controvertida. En otras palabras, que las soluciones a su modo de divertirse no surjan como una preocupación derivada de las quejas de los vecinos, sino de un entendimiento de las razones porque desean divertirse de un determinado modo.

\section{Comentarios sobre la construcción mediática de la realidad}

La juventud, como registro simbólico del imaginario colectivo, significa (la mayoría de las

9.- Es un término que se utiliza en España para referirse a las concentraciones de jóvenes en plazas y calles, especialmente los fines de semana, como forma de encuentro social en el que conversan y beben hasta altas horas de la madrugada. Este fenómeno ha tenido muy diversas manifestaciones sociales. Por un lado, se contempla "la movida" modelo de cultura que caracterizó al encuentro de jóvenes artistas a mediados de la década del setenta en diversas ciudades españolas. Destaca, por ejemplo, el caso de Madrid en la que participaron personajes como Pedro Almodóvar. Por el otro, también se refiere a otras versiones de la movida caracterizada por ciertas formas de civismo en las formas de ocupar el lugar público y que ha generado conflicto con los vecinos. Esta última es la examinada en el análisis que hacemos del tratamiento de los medios de comunicación. 
veces) ruptura del orden, afán de diversión y, otras, promesa del futuro, dependiendo de cómo quiera ser utilizada.

Cuando se producen episodios de desorden social de los que se desconocen sus causas, aparece rápidamente la hipótesis de la intervención de los jóvenes. Estos últimos son los responsables impersonales y genéricos del desorden y, por tanto, adquieren la presunción de sujetos privilegiados en la construcción informativa que persigue precisamente cualquier interrupción de la normalidad.

En cambio, curiosamente, cuando aparece cualquier administración en escena, los jóvenes pasan de responsables a víctimas de sus circunstancias sociales, por lo que aquellas pueden dejar constancia de un modo más plástico su actitud paternalista. Además, si antes los jóvenes se representaban con imágenes de incivismo (suciedad, bebida, alboroto), estas desaparecerán para dar lugar a la aparición del político que presenta una iniciativa para los jóvenes. Se pretende evitar que las imágenes peyorativas asociadas a estos puedan salpicarles, dando la impresión de sentirse responsables de los problemas. Estos pertenecen a una realidad convulsa y descompuesta que corresponde a ellos solucionar. Por eso, los titulares que recogen las iniciativas de las administraciones se presentan en afirmativo y futuro inmediato, por ejemplo, "los jóvenes dispondrán de un espacio para sus diversiones nocturnas", aunque todos sabemos que del dicho al hecho va un trecho. Sin embargo, a través de la información se le otorga realidad mediática a sus intenciones, que es lo único que llega a conocer la mayoría.

Por otra parte, los medios de comunicación manufacturan la realidad para cumplir con la auténtica función de los medios de comunicación: adular a sus destinatarios. Se trata de que el lector, cuando termine de leer el periódico, tenga la sensación aterciopelada de que el mundo es como él se lo imaginaba. Los medios tienen que ser aduladores sin que lo perciban los adulados para conseguir la cuota de consumo ideológico y social que le sea más afín.

Por tanto, el enfoque y contenido de las noticias no se dirige a los jóvenes, estos no son nada más que monedas de cambio estereotipadas para el manejo del público adulto. Los medios de comunicación son los grandes emisores de las conversaciones cotidianas que se suscitan no tanto con la intención de conocer acerca de lo que se habla, como de identificar o diferenciar con quién se habla. Es decir, los medios cumplen la función sociológica de informar, pero no para ser informados, sino para ser entretenidos con la información.

La imagen, desgraciadamente, más frecuente y tópica de los jóvenes en los medios de comunicación es la de la movida como ilustración de la falta de civismo ${ }^{10}$. Por supuesto,

10.- Hemos encontrado comentarios tan alentadores para la juventud como el siguiente: "No tengo la menor duda de que los cabezas rapadas se divierten golpeando en manada a personas indefensas. Estoy seguro de que los acosadores se divierten mientras perpetran sus atropellos. Y seguro que los miles de jóvenes que salen los fines de semana a beber, orinar y gruñir en las calles se divierten como pavos en un charco. Pero como las palizas, los acosos, la mugre y el bullicio son diferentes formas de agresión, los ciudadanos pacíficos tienen el derecho a exigirle al Estado que les proteja de esas agresiones. Tan justo y necesario es proteger a los inmigrantes del El Ejido de las alimañas racistas, como a los vecinos que están a merced de las alimañas nocturnas. Y es que sólo una alimaña puede producir en una noche un kilo de basura y sin contar sus secreciones". Desgraciadamente, suele ser 
no podemos negar los efectos negativos que la actividad juvenil puede ocasionar a los vecinos, pero es importante observar que este enfoque no atiende a las razones de la movida, sino a sus consecuencias. Si esta es la perspectiva que adoptan las administraciones, muy probablemente errarán en sus soluciones, pues sería como si un médico creyera que curar una enfermedad radica en anestesiar sus síntomas. Sería, quizás, una buena medida paliativa frente al dolor, pero no su solución.

Los medios de comunicación presentan la movida como una diversión que parece perseguir esencialmente la molestia al resto de la ciudadanía. Además, esta imagen es la que más conviene desde una perspectiva informativa, pues involucra a muy distintos agentes de la comunidad (vecinos, empresa de limpieza, instituciones, jóvenes) lo que permite establecer un diseño de su distinta función dentro de una narrativa de la convivencia. Por una parte, "los integrados" se presentan como titulares de derechos, mientras que, por otra, quienes no lo son se proyectan como parásitos a los que hay que tolerar. La juventud se concibe como una masa amorfa con las que se identifican las disfunciones de un sistema en las que hemos contribuido todos y, particularmente, la influencia del consumismo social adaptado también al ámbito del comportamiento.

Por tanto, los medios no juegan una postura conciliadora en el conflicto de la movida sino que, por el contrario, resaltan sus asperezas, lo que no conduce sino a una radicalización de las posiciones que, a su vez, beneficia las intenciones comerciales del medio, al convertirse estos en otro campo de batalla para jóvenes, vecinos e instituciones. El efecto no es otro que la categorización (estereotipo) de los jóvenes con la incomprensión que esta situación genera por parte del público adulto.

Por otro lado, falta en el tratamiento de los medios una perspectiva del joven, o sea, aportar soluciones desde la lógica de quienes lo ocasionan y no de quienes lo padecen, pues en teoría lo primero es necesario para lo segundo. Además, es un criterio deontológico básico escuchar a las partes afectadas. Sin embargo, se encuentra difícilmente la voz de los jóvenes en relación con sus problemas. En otras palabras, estos son meros objetos informativos y no sujetos y, para aspirar a una democracia informativa real, es preciso que también aquellos sobre los que se habla, hagan uso de la palabra.

Esta es la imagen más frecuente de la juventud en los medios, aunque no la única. También existe un tratamiento positivo reservado a aquellos que están en la cola que el propio sistema ha establecido para su ingreso, como son los jóvenes universitarios. Curiosamente, esta no parece tener en cuenta que la mayoría de los jóvenes de la movida son universitarios. En cambio, se escinden estas dos facetas de la juventud para un distinto propósito informativo. Mientras que en el caso de la botellona, la información responde a los prejuicios del público adulto a los que se dirige, las noticias de los cuadernillos universitarios (dirigidos a jóvenes) los presentan como esforzados, solidarios y críticos, de lo que se presume siempre sus razones, excepto cuando lo hacen en contra del gobierno, al menos para algunos medios. Por otra parte, no olvidemos que esta imagen positiva del joven universitario constituye, de facto, un reconocimiento social a su derecho a consumir lo que precisa para su formación, lo que dicha sección informativa se convierte en lugar privilegiado para empresas con

el tono con los que algunos medios tratan a los jóvenes. 
intereses publicitarios (coches, productos bancarios, viajes, cursos de formación, idiomas, entre otros).

También llama la atención el giro copernicano que supone el tratamiento de la juventud en el tiempo de campaña electoral. Su condición de nuevos votantes y su valor como símbolo de futuro son muy cuidados por todos los partidos (léase "medios afines") que convierten, por arte de magia, sus presuntos conflictos sociales en dificultades. Por ejemplo, no se trata de que "no se quieran ir de casa" y sean unos "vagos", sino que no hay manera de obtener una independencia socioeconómica digna.

\section{Conclusiones}

De las reflexiones que hemos esbozado en este trabajo, creemos que se puede traer una serie de conclusiones sobre el significado de la juventud en los medios de comunicación. Entre otras, podemos destacar los siguientes aspectos:

- La juventud" se ha convertido en un término comodín para explicar las más variadas circunstancias de desorden social. La juventud se maneja como una categoría social del "altercado", de tal suerte que ante la perplejidad por las posibles causas de unos hechos inciertos, el recurso a la juventud constituye una buena hipótesis para tranquilizar momentáneamente a la población. Por ejemplo, este uso de la juventud como categoría informativa del desorden público, se pudo comprobar en el tratamiento que se prestó a los episodios de la madrugá sevillana del 2000.

- Existe un uso genérico del término “joven” para referirse a quienes todavía se presume que no está integrado en el sistema social. Así, hemos llegado a encontrar casos en los que el actor de un delito se califica de joven, a pesar de sus 33 años. Pareciera que ser delincuentes es un mérito para ser considerado como joven, pues, con esta misma edad, quien accede al mercado laboral es ya un "hombre".

- En hechos delictivos en los que los jóvenes son presuntos autores, se procede con ligereza a la identificación de su nombre, apellido y, en ocasiones, foto. Cuando no, se acude a declaraciones de vecinos o a la especificación de circunstancias por las que podría ser fácilmente reconocido el autor de los hechos. No se respeta su intimidad cuando se da cuenta de asuntos de vida privada que no guardan ninguna relación con los hechos noticiosos. Parece que el propósito de esta información adicional consiste más en categorizar a un determinado tipo de joven con unos hechos que en su valor informativo ${ }^{11}$.

11.- El joven delincuente es el drogadicto, marginado y, normalmente, residente en zonas marginales. Estos datos suelen añadirse, a pesar de ser irrelevantes, porque el medio no sólo debe decir qué infracciones se producen, sino también quién las comete. Hay que marcar centro y periferia dentro del sistema de convivencia. Lo desviado o delictivo ocurre, pero se presenta como una exterioridad, como una agresión desde fuera y un problema que debe ser solucionado como si no perteneciera al orden constituido. Este tipo de joven, que Goodman (pp. 207 y ss.) caracteriza como "el fatalista prematuro", es, en esencia, un descubridor temprano de su falta de adecuación al sistema, por lo que optan por sobrevivir a su costa como un modo de definición de su "desintegración". En cierto sentido, ello le aporta "identidad", aunque sea como sujeto delictivo. El delincuente juvenil se caracteriza por saber que será atrapado, castigado y fichado, lo que parece contradictorio, pero no lo es. La reiteración de 
- Se informa de hechos delictivos cometidos por jóvenes, en ocasiones, extremadamente trágicos de un modo espectacular y sensacionalista. Este tipo de información puede propiciar comportamientos imitativos en otros jóvenes que, atraídos por su protagonismo, vean una vía de escape a su anonimato, aunque sea por la vía del delito.

- En general, los medios identifican la realidad de los jóvenes con los aspectos desviados y negativos de su comportamiento, por lo que se estigmatiza su imagen como una especie de mal endémico para la sociedad. Las imágenes que normalmente se asocian con los temas de juventud corresponden a escenas de la movida, sexo o consecuencias de sus actos de violencia y desmanes públicos. Si tenemos en cuenta que un alto porcentaje de los lectores de medios tan sólo leen el titular y ven la foto, podríamos decir que la impresión que saca de la juventud es claramente peyorativa.

- Esta escisión en la imagen de los jóvenes, ya sea por su dedicación o sea por el momento informativo que se pretende rentabilizar electoralmente, supone una clara señal de cómo los medios corresponden a una serie de intereses económicos y sociopolíticos que determinan el valor simbólico de los jóvenes en la información. A nuestro juicio, con estas distinciones tan maniqueas sólo se conduce a potenciar una diferencia de clase, acompañada de sus sentimientos propios, que en poco se compadece con el ideal democrático de la igualdad, el cual ha de procurar una dignificación de las personas al margen de una escenografía del poder social.

\author{
Apéndice: \\ Decálogo para mejorar la imagen de la juventud en \\ los medios de comunicación (Instituto Andaluz de la Juventud) ${ }^{12}$
}

\title{
EI Principio de Responsabilidad Social
}

Los Medios de Comunicación son educadores permanentes de la sociedad. Su responsabilidad no puede cifrarse exclusivamente en el cumplimiento de unos deberes garantes de los derechos de los ciudadanos, sino también en responsabilidades que contribuyan a poner en práctica valores positivos para un comportamiento cívico.

Los medios han de reconocer que la juventud es un periodo decisivo en la formación de las personas. Su reivindicación de una mayor autonomía con respecto a la generación precedente, suele ir acompañada de un efecto pendular que le conduce a valorar de manera desproporcionada nuevas experiencias que simbolicen su independencia. Estos

sus actos, la elevación de sus apuestas o su actuación en bandas, son elementos que conducen a ello. A su juicio, la lógica de dicho comportamiento, que lo asimila a "una especie de crisis religiosa de la adolescencia, con un contenido y una pasión de tipo religioso", lo que le llevaría a sentirse atraído por aquello que rechaza, ven en el castigo y el internamiento un modo de sentir una reacción del sistema hacia su realidad.

12.- Este decálogo fue elaborado por Juan Carlos Suárez en su formulación deontológica. Otros compañeros de esta investigación contribuyeron con ejemplos que permitían ilustrar el sentido de la recomendación deontológica formulada. 
espacios psicológicos suelen ser aprovechados por agentes económicos que edulcoran la programación, a fin de utilizarla de infraestructura comercial, y banalizan cuestiones fundamentales que pueden contribuir al desarrollo de un espíritu crítico de los más jóvenes.

Por esta razón, el Instituto Andaluz de la Juventud (IAJ), propone la adopción de un compromiso ético a los distintos agentes involucrados en la comunicación social, tanto a los responsables de las empresas periodísticas como a los profesionales de la información, con los objetivos de contribuir a la protección de los derechos de los jóvenes, fomentar proyectos comunicativos que atiendan a las necesidades de su etapa y a dotar de contenido sus aspiraciones y lograr la participación de los jóvenes en los escenarios mediáticos.

Con estas pretensiones, dentro de los marcos jurídicos y deontológicos que regulan los aspectos más básicos de la actividad informativa, se proponen en este libro una serie de deberes y responsabilidades específicas en relación con la juventud andaluza.

\section{Principios}

1) Evitar el abuso de generalizaciones y no caer en el uso de estereotipos cuando se informa u opina sobre los jóvenes. Sobre todo en temas relacionados con la violencia, la delincuencia o la droga.

Recomendaciones:

- Cuidar el uso del lenguaje, evitando expresiones o vocabularios peyorativos, racistas, machistas, etcétera.

- No emplear titulares del tipo: "Un joven acuchilla a una turista en el céntrico barrio de Santa Cruz"/ "Dos jóvenes menores delincuentes roban en una zapatería a plena luz del día"/ "Jóvenes drogadictos atracan una gasolinera en Cádiz". Más conveniente utilizar titulares del tipo: "Un hombre acuchilla a una turista en el céntrico barrio de santa Cruz"/ "Dos menores delincuentes roban en una zapatería a plena luz del día"/ "Drogadictos atracan una gasolinera en Cádiz"

- Prestar mayor atención al tratamiento gráfico y a la disposición de las imágenes para evitar que las actividades juveniles sólo se identifiquen gráficamente con situaciones incívicas o molestas.

2) No comparar a la juventud con otras realidades sociales que no guardan simetrías con sus condiciones sociales, evitando arrojar sobre ella responsabilidades que sólo son resultados de problemas de la sociedad, tales como la falta de empleo o la mayor relajación en actitudes consumistas en las que han sido educados.

\section{Recomendaciones:}

- Evitar contrastes gratuitos entre los jóvenes y el público adulto, de manera que resulte que la responsabilidad parezca una razón del desafuero de los otros. Esta perspectiva, además de ser injusta, sin tener en cuenta las dificultades que atraviesa la juventud actual para incorporarse al sistema, propicia actitudes de exclusión que pueden motivar la protesta más o menos enérgica hacia una sociedad en la que se siente incomprendida.

- Cuidar que la catalogación informativa que se pueda hacer de los jóvenes no constituya un discurso que favorezca la desigualdad social entre ellos, permitiéndose, en unos 
casos, licencias informativas que perjudiquen a los más desfavorecidos, mientras que en otros se adoptan actitudes de respeto propias de granjearse la confianza de un cliente (A este respecto, cabe advertir la diferencia que se establece, por ejemplo, entre el joven de la denominada movida y el universitario, cuando en un alto porcentaje es el mismo).

3) No violar los derechos de su personalidad por razón de la juventud, como si esta condición fuese una agravante de sus propios actos.

Recomendaciones:

- Se ha de cuidar la alusión a datos personales, como el nombre, domicilio u otras circunstancias que contribuyan a la identificación del joven relacionado con actos delictivos o de marginación social, ya que la difusión de estos datos pueden afectar a su posterior desarrollo psíquico y social.

- Se ha de tener en cuenta si la alusión a la condición de joven permite una mayor claridad en la exposición de la noticia o si, por el contrario, no es más que un aspecto accesorio que sólo contribuye a utilizar a la juventud como un mero código informativo que simboliza el desorden y lo imprevisible.

- Evitar hipótesis gratuitas en las que se especule con la juventud como causante de situaciones insólitas o desconocidas, como si fuera parte de su dinámica social.

- No transmitir imágenes de menores que hayan sido autores, testigos o víctimas de delitos $\mathrm{y}$, en todo caso, a garantizar su absoluto anonimato.

- No utilizar a jóvenes con graves patologías, o portadores de minusvalías, para hacer propaganda de terapias de un modo sensacionalista.

- No entrevistar a jóvenes en situaciones de grave crisis (por ejemplo, que hayan huido de casa, que hayan intentado el suicidio, que sean explotados por la criminalidad adulta, que estén involucrados en un ambiente de prostitución, que tengan a sus padres en la cárcel y, en todo caso, garantizar su absoluto anonimato).

4) El periodista debe tomar conciencia y reflexionar sobre la importancia que su ejercicio profesional tiene en la transmisión de la imagen del colectivo juvenil en Andalucía.

Recomendación:

- Debe tener presente que la población juvenil responde a una realidad muy heterogénea, al igual que otros grupos de edad, con los que no se suelen establecer estereotipos.

5) Denunciar aquellas situaciones sociales, laborales o de cualquier otra índole que puedan obstaculizar el desarrollo de los derechos de los jóvenes.

Recomendaciones:

- Informar sobre situaciones de precariedad y explotación laboral que los jóvenes no se atreven a denunciar por no ver frustradas sus aspiraciones a integrarse en el sistema

- Denunciar situaciones educativas que contribuyan a desincentivar a los jóvenes en su empeño para formarse, ya sea por dificultades materiales o administrativas que se lo impidan. 
6) Destacar valores de los jóvenes, especialmente difundiendo actividades importantes e iniciativas positivas. En esta línea, conviene promocionar una información del colectivo juvenil basada en sus aportaciones favorables y productivas a la sociedad o, cuando menos, que estas superen a las que puedan tener un carácter peyorativo de su imagen.

Recomendaciones:

- Dar mayor voz a colectivos juveniles como voluntarios, asociaciones de jóvenes emprendedores, universitarios, opositores, jóvenes trabajadores, etcétera.

- Fomentar las informaciones referidas a la realización de actividades de carácter laboral o cultural que permitan ilustrar a otros jóvenes y le incentiven a emularlas.

7a) Dedicar mayor espacio en los medios de comunicación a aquellos temas que realmente interesan a los jóvenes. El colectivo juvenil necesita información constante y no sólo recogida eventualmente en los suplementos.

Recomendación:

- Reclamar, especialmente a los empresarios de los medios de comunicación, un compromiso para la creación de espacios de información, dedicados y realizados por jóvenes. Ejemplo: los jóvenes becarios de la Facultad de Ciencias de la Comunicación de Málaga elaboran el suplemento semanal "La Crónica Universitaria", del Sur de Málaga. En este sentido, el IAJ ha premiado la labor de esta iniciativa, con el premio "Málaga Joven 2003".

7b) Favorecer una mayor igualdad de género en la comunicación dirigida a los jóvenes, evitando asociaciones tan tradicionales como injustas sobre el hombre y la mujer.

Recomendaciones:

- Prestar cuidado a las imágenes de archivo con la que se cubren las informaciones sobre las dedicaciones profesionales de hombres y mujeres.

- Potenciar que la mujer aparezca como una profesional cualificada y experta en las materias sobre la que se consulta, función en la que todavía predomina el género masculino.

- Modificar propuestas publicitarias que continúan atendiendo a la idea de éxito basado en la obtención de la mujer como un premio social o sexual.

8) Facilitar una mayor participación de "la voz" los jóvenes en los medios de comunicación. Para ello, hay que intentar que los propios jóvenes formen parte de la realidad informativa.

Recomendaciones:

- Incorporar a los jóvenes como parte de los debates políticos y sociales de actualidad.

- Por su parte, el joven debe asumir un papel más activo, reclamando rigor y profesionalidad en las informaciones que le afecten. Este papel implica que los jóvenes acudan a los 
medios para promocionar las acciones positivas que están realizando, así como la expresión de sus inquietudes

9) Utilizar a los jóvenes como fuente informativa en aquellas noticias en las que sean protagonistas.

Recomendaciones:

- Junto a las fuentes convencionales el periodista puede complementar sus informaciones, acudiendo a los colectivos juveniles (asociaciones, colectivos universitarios y estudiantiles, voluntariado...).

- Incluir a los jóvenes en los escenarios domésticos como un agente con derechos pero también con responsabilidades, aspecto que normalmente no se incluye en los documentales sobre la juventud.

10) Difundir informaciones sobre las campañas que ponen en marcha las administraciones, así como las entidades públicas y privadas, para el fomento de hábitos de vida saludable entre los jóvenes. Aunque estas campañas comprenden un gran número de acciones para llegar hasta el colectivo joven, los medios tienen un importante papel como canales difusores del mensaje preventivo que se pretende trasladar a la sociedad.

Recomendaciones:

- Propiciar debates, monográficos, coloquios, entrevistas o reportajes sobre hábitos de vida saludable: prevención de accidentes de tráfico, consumo de drogas, enfermedades de transmisión sexual, embarazos no deseados, trastornos alimenticios...

- Complementar estas informaciones utilizando como fuentes a especialistas en la materia, con el fin de que la temática en cuestión sea tratada con el mayor rigor. 


\section{Fuentes consultadas}

Aranguren, J. L. (1961). La juventud europea y otros ensayos. Barcelona: Seix Barral.

Auge, M. (1993). Los no lugares. Una antropología de la sobremodernidad. Barcelona: Gedisa.

Bourdieu, P.

_(1997). Sobre la televisión. Barcelona: Anagrama.

_(1991). La distinción. Criterio y bases sociales del gusto. Madrid: Taurus.

_(1990). “La juventud es más que una palabra”. En Sociología y cultura. México D. F.: Grijalbo.

Calvo, T. (1995). Crece el racismo, también la solidaridad. Las actitudes de nuestros jóvenes ante otros pueblos y culturas. Madrid: Tecnos.

Ericson, E. H. (1980). Identidad (Juventud y crisis). Madrid: Taurus.

Feixa, C. (1999). De jóvenes, bandas y tribus. Antropología de la juventud. Barcelona: Ariel.

Foulcault, M. (1990). Vigilar y castigar. Madrid: Siglo XXI.

Garrido Medina, L. y Gil Calvo, E. (1993). Estrategias familiares. Madrid: Alianza Universidad.

Gil Calvo, E. (1985). Los depredadores audiovisuales. Juventud urbana y cultura de masa. Madrid: Tecnos.

Goodman, P (1971). Problemas de la juventud en la sociedad organizada. Barcelona: Península.

Gubern, R.

_(1977). Comunicación y cultura de masas. Barcelona: Península.

_(1987). La mirada opulenta. Barcelona: Gustavo Gili

Iglesia de Ussel, J. (1998). La familia y el cambio político en España. Madrid: Tecnos.

Maffesoli, M. (1990). El tiempo de las tribus. Barcelona: Icària.

Maluf, N. A. (1999). "Bellos pero irresponsables". En Iconos, 8. Quito: Flacso.

Miguel de, A. (2000). Dos Generaciones de jóvenes 1960-1998. Instituto de la Juventud.

Morin, E. (1994). Introducción al pensamiento complejo. Barcelona: Gedisa.

Ortega y Gasset, J

_(1992). La rebelión de las masas. Madrid: Alianza.

_(1982). Misión de la Universidad. Madrid: Alianza.

Pérez Tornero J. M. (1994). El desafio educativo de la televisión. Barcelona: Paidós.

Sánchez Noriega, J. L. (1997). Crítica de la seducción mediática. Madrid: Tecnos. 
Schiller, H. (1987). Los manipuladores de cerebros. Barcelona: Gedisa.

Sperber, D. (1988). El simbolismo en general. Barcelona: Anthropos.

Suárez, J. C. (2001). Análisis Ético de la Información. Sevilla: Mad.

Van Dijk, T. A. (1990). La noticia como discurso (comprensión, estructura y producción de la información). Barcelona: Paidós. 